\title{
Redes neurais artificiais aplicadas na correlação entre óbitos de dengue, automedicação e fatores abióticos em Goiânia-Goiás
}

\author{
Artificial neural networks applied in the correlation between dengue deaths, self-medication and \\ abiotic factors in Goiânia-Goiás \\ E. O. Nascimento ${ }^{1}$; R. G. Costa ${ }^{2}$; L. N. Oliveira ${ }^{1 *}$ \\ ${ }^{1}$ Instituto de Educação, Ciência e Tecnologia de Goiás-Campus Goiânia; \\ ${ }^{2}$ Departamento de Farmácia da Pontifícia Universidade Católica de \\ Goiás; \\ *lucas@ifg.edu.br
}

(Recebido em 12 de novembro de 2016; aceito em 5 de março de 2017)

\begin{abstract}
Este artigo visa verificar de forma inédita, por meio de um estudo explanatório, as possíveis correlações ainda não bem esclarecidas entre óbitos de dengue e fatores abióticos, como condições climatológicas e a influência da automedicação, para a cidade de Goiânia-GO. Para tanto, foram coletados dados governamentais destas variáveis entre 2005 e 2015 e para realizar uma aproximação multidimensional destes dados aplicou-se as Redes Neurais Artificiais (RNAs), na arquitetura Perceptron Multicamadas, otimizada pelo Algoritmo de Levenberg-Marquardt; realizando a construção e o estudo com seis topologias. Para obter a significância da correlação entre as variáveis de entrada da RNA foram propostas modificações do Método Profile. Os resultados mostraram que existe uma grande influência da automedicação e precipitação pluviométrica como principais impactantes nos óbitos, já a temperatura foi classificada com moderada significância. Dessa maneira, conclui-se que as RNAs podem ser aplicadas de forma satisfatória em problemas de modelagem epidemiológica.
\end{abstract}

Palavras-chave: Dengue, Redes Neurais Artificiais, Automedicação.

This article aims to verify in an unprecedented manner by means of an explanatory study the possible correlations that still not well understood between dengue deaths and abiotic factors, like climatic conditions and the influence of self-medication, it was analyzed for the city of Goiania-Go Brazil. Thus, it was collected government data for these variables between 2005 and 2015, and then were performed a multidimensional approximation on these data by the Artificial Neural Networks (ANN), using the Multilayer Perceptron architecture, optimized by the algorithm of Levenberg-Marquardt, and it was performed the design and studied of six topologies. For calculate the significance of the correlation between the input variables of the ANN was proposed modifications to Profile method. The results showed that there is a large influence of self-medication and precipitation as the main striking in deaths, the temperature were classified as moderate significance. Thus, it was concluded that the ANN could be applied satisfactorily in modeling epidemiological problems.

Keywords: Dengue, Artificial Neural Networks, Self-medication.

\section{INTRODUÇÃO}

A dengue é uma virose aguda e de cunho sistêmico com etiologia viral, transmitida pelo vetor Aedes aegypti da família Flaviviridae, que corresponde aos seguintes sorotipos DENV-1, DENV2, DENV-3 e DENV-4 [1]. Teixeira et al. (1999) [2] mostraram que as primeiras epidemias de dengue ocorreram no Egito e na Ilha de Java, em Jacarta, ambas em 1779, e na Filadélfia nos EUA em 1780. No Brasil, há registros da presença deste vírus no século XVI no período colonial e, a partir do século XX, o combate ao Aedes aegypti tornou-se sistematizado em todas as regiões brasileiras [3]. A ocorrência da dengue relaciona-se com o fenômeno da urbanização desordenada e das condições climáticas, tais como o índice de pluviosidade, a umidade relativa do ar e a temperatura que podem favorecer o desenvolvimento do vetor e criadouros [4].

Além dos fatores sócio demográficos e climáticos, diversas pesquisas mostraram que o uso irracional de medicamentos configura-se como um fator de risco associado aos óbitos decorrentes das complicações da dengue, como os quadros hemorrágicos [5, 6, 7]. Neste sentido, cabe uma avaliação quantitativa do risco em potencial associado a esta automedicação. Por sua vez, o diagnóstico precoce da dengue é de difícil determinação, visto que seus primeiros sintomas são 
facilmente confundidos com outras doenças febris e exantemáticas [8]. Comumente, as primeiras recomendações diante destes quadros, seja por dengue ou outras doenças com sintomatologia similar, é a administração de antipiréticos e analgésicos e, de mesmo modo, em decorrência de sintomas considerados menores, as pessoas se automedicam, agravando-se uma doença já estabelecida e pondo assim em risco sua saúde $[9,10]$.

Neste contexto, diversos estudos sinalizam que a dipirona, ácido acetilsalicílico e o diclofenaco pertencentes aos anti-inflamatórios não-esteroidais (AINE) e os suplementos vitamínicos, configuram-se como os mais utilizados na automedicação [11, 12], uma vez que estes são isentos de prescrição e de fácil acesso nas prateleiras das farmácias brasileiras [13]. Sabe-se que o ácido acetilsalicílico não é prescrito após o diagnóstico de dengue, restando algumas opções de antipiréticos e analgésicos [14]. Dentre estas opções, a utilização de dipirona torna-se preocupante pois pode levar ao desenvolvimento de quadros hemorrágicos como mostrou Diaz-Quijano (2014) [15].

Dessa forma, o Ministério da Saúde [16] relatou que houve um significativo aumento do número de registros de dengue no país. Esta enorme quantidade de casos impacta diretamente na operacionalidade do Sistema Único de Saúde (SUS) [17]. Existe a necessidade de um estudo que aponte os principais fatores que impactam na proliferação de dengue, pois este atuará de forma otimizada na determinação das principais causas desta epidemia, o que poderá evitar inúmeros óbitos por ações preventivas.

Este trabalho visa quantificar, por meio das Redes Neurais Artificiais (RNA) [18], a significância da contribuição funcional dos fatores climáticos, sócio demográficos e a automedicação na incidência de mortalidade por dengue, no período entre 2005 e 2015 na cidade de Goiânia-GO. Realizou-se um estudo de caráter explanatório nos dados disponibilizados por órgãos governamentais ao aplicar nas RNA uma modificação do Método Profile [19], a fim de obter de forma inédita as correlações não-lineares intrínsecas a estes dados. Propõe-se contrapor e/ou validar as análises de causa e efeito ou generalizações estatísticas conforme a abordagem tradicional nos estudos que relacionam a identificação de fatores com o desenvolvimento de dengue [20, 21, 22].

\section{MATERIAL E MÉTODOS}

A metodologia é composta de duas segmentações, a primeira refere-se sobre a forma de obtenção dos dados experimentais onde são esclarecidos os principais indícios da escolha destas variáveis. A segunda segmentação norteia sobre a aplicabilidade dos métodos numéricos que usam as Redes Neurais como um modelo de fitting nos dados experimentais. Após esta fase, aplicou-se o algoritmo do Método Profile para se obter a significância em termos da sensibilidade da saída do sistema em função dos parâmetros das entradas. Objetivou-se, dessa forma, estabelecer uma correlação entre as entradas numéricas que foram o índice de automedicação (IAM), notificações de dengue (ND), precipitação $(P)$, temperatura média compensada $(T M C)$ e a quantidade de dias com precipitação mensal $(D C P M)$, esta última reflete a quantidade de dias com a presença de precipitação num mês. Como variável de saída, avaliou-se a quantidade de óbitos $(Q O)$, provenientes de dengue.

Nas seções 2.1 à 2.6, são apresentadas detalhes da construção dessas duas segmentações, sendo que as seções 2.1 à 2.4 referem-se a primeira delas.

\subsection{Evolução da dengue em Goiânia}

Segundo Maciel [1], os primeiros casos notificados de dengue foram registrados em $1994 \mathrm{com}$ os seguintes sorotipos DENV-1, DENV-2 e DENV-3. Desde então, inúmeras epidemias ocorreram e, apesar das flutuações nos casos durante o período de 2005 a 2015, percebe-se um aumento significativo das notificações, sendo que em 2005 foram 8025 casos notificados contra os 74259 em 2015 (Tabela 1). Neste cenário de notificações no município de Goiânia também constata-se, por meio de um comparativo entre as notificações e os óbitos de dengue, que não há uma relação diretamente proporcional entre estas variáveis. Sugere-se que deva haver fatores exógenos correlacionados, cuja a dinâmica destes não está bem esclarecida. 
Tabela 1: Evolução dos casos notificados de dengue e o óbitos em Goiânia durante 2005-2015.

\begin{tabular}{cccccccccccc}
\hline & \multicolumn{10}{c}{ Ano } \\
\cline { 2 - 12 } & $\mathbf{2 0 0 5}$ & $\mathbf{2 0 0 6}$ & $\mathbf{2 0 0 7}$ & $\mathbf{2 0 0 8}$ & $\mathbf{2 0 0 9}$ & $\mathbf{2 0 1 0}$ & $\mathbf{2 0 1 1}$ & $\mathbf{2 0 1 2}$ & $\mathbf{2 0 1 3}$ & $\mathbf{2 0 1 4}$ & $\mathbf{2 0 1 5}$ \\
\hline Notificações & 8254 & 11268 & 5888 & 21404 & 20783 & 39552 & 12421 & 9729 & 53433 & 25491 & 74259 \\
Óbitos & 8 & 12 & 10 & 24 & 22 & 21 & 18 & 32 & 23 & 24 & 38 \\
\hline
\end{tabular}

Fonte: DATASUS/SINAN/DVE/DVS/SMS-Goiânia [23, 24].

De posse dessas informações anuais da Tabela 1, foi realizado uma estratificação mensal dos casos notificados de dengue, conforme mostrado na Tabela 2. Estes dados foram obtidos por meio do Boletim Epidemiológico do Município de Goiânia pela Secretária Municipal de Saúde da prefeitura de Goiânia e pelo sistema DATASUS/SINAN/DVE/DVS/SMS-Goiânia [23, 24].

Tabela 2: Estratificação mensal dos casos notificados de dengue (ND) em Goiânia.

\begin{tabular}{|c|c|c|c|c|c|c|c|c|c|c|c|c|}
\hline \multirow[b]{2}{*}{ Ano } & \multicolumn{12}{|c|}{ Meses } \\
\hline & jan. & fev. & mar. & abr. & maio & jun. & jul. & ago. & set. & out. & nov. & dez. \\
\hline 2005 & 232 & 748 & 1725 & 2210 & 1686 & 539 & 147 & 155 & 103 & 168 & 393 & 554 \\
\hline 2006 & 2106 & 2705 & 2435 & 1935 & 1369 & 262 & 96 & 79 & 57 & 127 & 246 & 145 \\
\hline 2007 & 715 & 1179 & 1713 & 654 & 532 & 286 & 163 & 116 & 61 & 178 & 242 & 353 \\
\hline 2008 & 927 & 1524 & 4586 & 8548 & 3686 & 741 & 242 & 184 & 129 & 277 & 564 & 653 \\
\hline 2009 & 1324 & 2199 & 3863 & 3128 & 2294 & 969 & 504 & 1008 & 593 & 950 & 3176 & 3893 \\
\hline 2010 & 14187 & 10774 & 5612 & 2450 & 1583 & 497 & 365 & 679 & 994 & 1280 & 1717 & 1732 \\
\hline 2011 & 1918 & 2279 & 2139 & 1685 & 1486 & 559 & 407 & 495 & 431 & 789 & 967 & 527 \\
\hline 2012 & 962 & 1121 & 1385 & 1109 & 1317 & 764 & 461 & 474 & 421 & 449 & 808 & 1241 \\
\hline 2013 & 9005 & 13683 & 15449 & 7273 & 3452 & 1242 & 546 & 560 & 462 & 650 & 1158 & 1201 \\
\hline 2014 & 2381 & 3240 & 3882 & 3841 & 4719 & 1703 & 983 & 1086 & 700 & 1001 & 1531 & 1870 \\
\hline 2015 & 5842 & 9549 & 19040 & 11949 & 16537 & 5886 & 1894 & 1256 & 845 & 736 & 358 & 205 \\
\hline
\end{tabular}

Contudo, mesmo com a presença dos dados mensais, objetiva-se nesta pesquisa utilizar dados com uma maior resolução temporal, isto é, aumentar a quantificação dos dados de notificação em um menor período de tempo possível com intuito de visar a posterior suplementação destes como o conjunto de amostras submetidas ao treinamento das Redes Neurais. Sendo assim, adotou-se como unidade da escala temporal os dados em termos de notificações diárias, ou seja, o primeiro dia de janeiro de 2005 - (01/01/2005) representa o dia 1 da escala, e o último dia do mês dezembro de 2015 - (31/12/2015) corresponde ao dia 4015 da escala temporal.

Na seção 2.4, será mostrada como foi realizado esta aproximação do número de dias, em termos dos dados de entrada para a RNA.

\subsection{Relação entre a análise demográfica e a automedicação}

Com base nos dados disponibilizados pelo Instituto Brasileiro de Geografia e Estatística (IBGE), avaliou-se em termos quantitativos o crescimento anual da população do município Brasileiro de Goiânia, pertencente ao Estado de Goiás. Logo, tem-se na Tabela 3, o quantitativo da população da referida cidade, durante o período de 2005 a 2015.

Tabela 3: Crescimento populacional de Goiânia - GO.

\begin{tabular}{|c|c|c|c|c|c|c|c|c|c|c|c|}
\hline & \multicolumn{11}{|c|}{ Ano } \\
\hline & 2005 & 2006 & 2007 & 2008 & 2009 & 2010 & 2011 & 2012 & 2013 & 2014 & 2015 \\
\hline População* & 1.201 & 1.220 & 1.245 & 1.265 & 1.282 & 1.302 & 1.318 & 1.334 & 1.394 & 1.412 & 1.431 \\
\hline
\end{tabular}

Nota-se que os dados da população no ano de 2007 foram obtidos através de contagem populacional e no ano de 2010 foi determinado por meio do Censo Demográfico. Nos demais anos foram estimados segundo metodologia própria do IBGE [25].

Castro et al. (2007) [5] revelaram que a automedicação no Estado de São Paulo atingiu 42,1\% da população, Antunes et al. (2008) [26] avaliaram que 80,5\% dos idosos de um grupo de pesquisa numa cidade de Santa Catarina automedicavam-se. Consequentemente sobre a população de 
Anciões, Monteiro et al. [27], por meio de um estudo transversal realizado numa cidade do Maranhão, verificaram que 67,0 \% cometiam uso indevido de medicamentos. Para Paim et al. (2016) [28], inúmeras pesquisas trazem níveis alarmantes de automedicação [28].

Em Goiânia, um estudo com 934 idosos, verificou por meio de questionários que 35,7\% cometiam automedicação [29]. Outro estudo analisando 211 universitários mostrou que 38,8\% automedicavam-se, sendo a Dipirona o medicamento principal $(59,8 \%)$ [30]. Um estudo realizado com 1480 pessoas entrevistadas em 12 capitais brasileiras no ano 2014, apontou que 65\% da população de Goiânia fez uso indevido de medicamentos [31]. Entretanto, estes $65 \%$ da população não foram caracterizados como um parâmetro dinâmico ao longo dos anos. Ocorre uma variabilidade estocástica e, para modelar estes fatores incontroláveis dadas as incertezas estatísticas associadas a obtenção do percentual da população que faz o uso irracional de medicamentos, é que foi estimada uma população dinâmica diária, que abrange o período entre 2005 e 2015, sendo este dado usado como o fator que abrange o IAM. Será apresentada na seção $2.4 \mathrm{o}$ aporte metodológico para a obtenção desta população.

\subsection{Tratamento dos dados climáticos}

Nesta pesquisa foram avaliados computacionalmente os efeitos climáticos para a cidade de Goiânia, capital do Estado de Goiás, localizado na região Centro-Oeste do Brasil (16 40' 43" S e $49^{\circ} 15^{\prime} 14^{\prime \prime} \mathrm{W}$ ), com altitude: $749 \mathrm{~m}$, cobrindo uma área de $743 \mathrm{~km}^{2}$. Seu clima é basicamente regido por duas estações sazonais, o período de seca, estendendo-se durante os meses de maio a setembro e o chuvoso estendendo-se de outubro a abril [32]. O clima desta apresenta diferentes especificidades para as variáveis climatológicas, ocorrendo dessa forma significativas mudanças altamente não lineares durante o ciclo anual. Nesta pesquisa, analisa-se o comportamento dinâmico dessa climatologia de acordo com dados de $P(\mathrm{~mm}), T M C\left({ }^{\circ} \mathrm{C}\right)$ e a $D C P M$. Tem-se nas Tabelas 4, 5 e 6 , respectivamente, os valores nominais dessas variáveis climatológicas durante o Período de $01 / 01 / 2005$ até $31 / 12 / 2015$.

Tabela 4: Dias com precipitação por mês - DCPM.

\begin{tabular}{|c|c|c|c|c|c|c|c|c|c|c|c|c|}
\hline \multirow[b]{2}{*}{ Ano } & \multicolumn{12}{|c|}{ Meses } \\
\hline & jan. & fev. & mar. & abr. & maio & jun. & jul. & ago. & set. & out. & nov. & dez. \\
\hline 2005 & 25 & 13 & 29 & 7 & 2 & 1 & 0 & 1 & 9 & 16 & 21 & 24 \\
\hline 2006 & 14 & 19 & 25 & 14 & 4 & 0 & 0 & 2 & 8 & 26 & 19 & 25 \\
\hline 2007 & 20 & 22 & 10 & 9 & 2 & 1 & 2 & 0 & 2 & 10 & 16 & 22 \\
\hline 2008 & 23 & 23 & 24 & 13 & 5 & 0 & 0 & 0 & 6 & 8 & 20 & 21 \\
\hline 2009 & 18 & 15 & 18 & 15 & 4 & 5 & 1 & 3 & 12 & 16 & 19 & 26 \\
\hline 2010 & 17 & 15 & 20 & 6 & 0 & 1 & 0 & 0 & 2 & 10 & 18 & 21 \\
\hline 2011 & 20 & 17 & 25 & 12 & 0 & 2 & 0 & 0 & 1 & 21 & 17 & 26 \\
\hline 2012 & 24 & 18 & 19 & 19 & 4 & 4 & 2 & 0 & 5 & 8 & 22 & 16 \\
\hline 2013 & 22 & 16 & 16 & 8 & 5 & 5 & 0 & 1 & 2 & 14 & 20 & 22 \\
\hline 2014 & 20 & 16 & 20 & 12 & 3 & 3 & 1 & 1 & 4 & 14 & 19 & 22 \\
\hline 2015 & 21 & 16 & 20 & 11 & 2 & 3 & 1 & 0 & 3 & 13 & 19 & 21 \\
\hline
\end{tabular}

Fonte: BDMEP [34], adaptado pelos autores.

Os dados das Tabelas 4, 5 e 6 foram obtidos através do Banco de Dados Meteorológicos para Ensino e Pesquisa (BDMEP), disponibilizadas pelo Instituto Nacional de Meteorologia (INMET) [33]. Estes foram adquiridos por meio das estações meteorológicas convencionais. Para mais detalhes sobre a metodologia e descrição das variáveis climáticas, recomenda-se o trabalho de [34]. 
Tabela 5: Precipitação* mensal em Goiânia - P

\begin{tabular}{|c|c|c|c|c|c|c|c|c|c|c|c|c|}
\hline \multirow[b]{2}{*}{ Ano } & \multicolumn{12}{|c|}{ Meses } \\
\hline & jan. & fev. & mar. & abr. & maio & jun. & jul. & ago. & set. & out. & nov. & dez. \\
\hline 2005 & 238 & 176 & 526 & 50 & 34 & 3 & 0 & 3 & 56 & 91 & 270 & 460 \\
\hline 2006 & 138 & 217 & 319 & 206 & 20 & 0 & 0 & 11 & 84 & 283 & 188 & 238 \\
\hline 2007 & 200 & 267 & 87 & 60 & 9 & 5 & 6 & 0 & 2 & 56 & 223 & 180 \\
\hline 2008 & 281 & 294 & 374 & 202 & 53 & 0 & 0 & 0 & 52 & 109 & 198 & 246 \\
\hline 2009 & 179 & 148 & 186 & 258 & 41 & 31 & 2 & 17 & 71 & 196 & 195 & 444 \\
\hline 2010 & 98 & 208 & 190 & 188 & 0 & 14 & 0 & 0 & 17 & 108 & 282 & 450 \\
\hline 2011 & 288 & 240 & 367 & 62 & 0 & 15 & 0 & 0 & 1 & 300 & 245 & 293 \\
\hline 2012 & 467 & 358 & 268 & 176 & 40 & 18 & 3 & 0 & 57 & 93 & 225 & 189 \\
\hline 2013 & 354 & 125 & 235 & 44 & 44 & 7 & 0 & 1 & 33 & 135 & 274 & 531 \\
\hline 2014 & 144 & 188 & 361 & 325 & 20 & 0 & 16 & 0 & 31 & 69 & 171 & 338 \\
\hline 2015 & 74 & 225 & 312 & 204 & 71 & 0 & 3 & 4 & 30 & 18 & 355 & 208 \\
\hline
\end{tabular}

* Precipitação dada em $m m$, Fonte: BDMEP [34], adaptado pelos autores.

Tabela 6: Temperatura* Média Compensada em Goiânia - TMC.

\begin{tabular}{|c|c|c|c|c|c|c|c|c|c|c|c|c|}
\hline \multirow[b]{2}{*}{ Ano } & \multicolumn{12}{|c|}{ Meses } \\
\hline & jan. & fev. & mar. & abr. & maio & jun. & jul. & ago. & set. & out. & nov. & dez. \\
\hline 2005 & 24,8 & 25,6 & 24,5 & 25,8 & 23,3 & 22,7 & 22,5 & 24,6 & 26,7 & 27,2 & 24,6 & 24,0 \\
\hline 2006 & 25,6 & 24,5 & 24,3 & 24,5 & 22,7 & 22,4 & 22,4 & 25,4 & 25,6 & 24,7 & 25,0 & 24,9 \\
\hline 2007 & 25,0 & 24,5 & 25,9 & 25,5 & 23,2 & 22,8 & 23,4 & 24,6 & 27,6 & 27,6 & 25,5 & 24,6 \\
\hline 2008 & 24,2 & 24,3 & 23,9 & 24,6 & 23,0 & 22,4 & 22,0 & 25,0 & 26,1 & 26,8 & 25,0 & 24,5 \\
\hline 2009 & 25,2 & 25,1 & 25,1 & 24,0 & 23,5 & 21,8 & 23,4 & 24,3 & 26,0 & 25,2 & 25,4 & 24,1 \\
\hline 2010 & 25,4 & 25,9 & 25,2 & 25,0 & 23,8 & 22,7 & 24,0 & 24,4 & 27,6 & 26,5 & 24,6 & 24,7 \\
\hline 2011 & 24,7 & 24,8 & 24,1 & 25,2 & 23,8 & 22,2 & 23,1 & 25,5 & 27,0 & 24,1 & 24,5 & 23,8 \\
\hline 2012 & 23,3 & 24,1 & 25,0 & 25,1 & 23,0 & 23,5 & 22,8 & 24,0 & 26,7 & 27,4 & 24,9 & 26,1 \\
\hline 2013 & 24,3 & 25,4 & 25,5 & 24,6 & 24,1 & 23,6 & 22,7 & 24,3 & 26,3 & 25,9 & 25,0 & 24,7 \\
\hline 2014 & 25,6 & 25,1 & 24,3 & 24,9 & 23,8 & 23,0 & 22,7 & 25,0 & 27,2 & 27,7 & 25,4 & 24,5 \\
\hline 2015 & 26,8 & 24,8 & 24,0 & 24,9 & 23,5 & 23,2 & 23,6 & 25,2 & 27,7 & 29,0 & 26,6 & 26,2 \\
\hline
\end{tabular}

${ }^{*}$ Temperatura dada em ${ }^{0} \mathrm{C}$, Fonte: BDMEP [34], adaptado pelos autores.

\subsection{Pré-processamento das variáveis de entrada e saída}

Foi aplicada a Regressão Linear (RL) nos dados da Tabela 3, com o objetivo de estimar os 65\% da população que pratica automedicação no regime de tempo diário em Goiânia durante 2005 e 2015. Estimou-se a população em cada um dos 4015 dias, considerando cada ano com 365 dias. Justifica-se a aplicação da RL [35] pois este método apresenta maior robustez frente a estimativa de um valor médio da vizinhança dos dados populacionais. Por meio dessa pré-estimativa, aplicouse a multiplicação de um conjunto randômico normalizado de uma distribuição normal com desvio padrão igual a média. A magnitude deste fator de multiplicação foi tomada como o maior erro residual entre a regressão linear e os dados coletados na Tabela 3. A introdução desta multiplicação dá-se para a estimativa da variabilidade estatística da automedicação, adotada para obter os dados de automedicação expressos pela variável IAM.

Posterior a determinação das variáveis de entrada para a RNA, presentes nas Tabelas 2, 3, 4 e 5, que representam respectivamente as variáveis $N D, I A M, D C P M, P$ e $T M C$ e como variável de saída da rede neural, usou-se a $Q O$, presente na Tabela 3. Houve a necessidade de realizar préprocessamento dos dados de entrada para a implementação numérica da rede neural objetivando aumentar a quantidade amostral de dados.

Para tanto, quando foi analisado a variável IAM, foi discutido através do Método da Regressão Linear. Todavia, para os conjuntos dos dados climáticos e dos índices da dengue, uma hipótese de relação linear não aplica-se de maneira adequada pois pelo próprio desvio padrão dos dados notase uma relação não-linear. Contrapondo este obstáculo, optou-se pelo uso da interpolação pelo Método Cubic Spline, com polinômios de terceira ordem, e coeficiente de suavidade de aproximação tendendo a unidade [36]. Dessa forma, foi feita uma rotina no programa $₫$ Matlab para implementar interpolação dos dados de entradas objetivando gerar um conjunto de 4015 amostras, 
correspondentes aos dias entre 01/01/2005 e 31/12/2015. Usou-se deste artifício para aumentar a quantidade de dados de entrada para a futura aplicação da Rede Neural, que será devidamente demonstrada na seção 2.5 .

\subsection{Aplicação e dimensionamento das Redes Neurais Artificiais}

As RNAs podem ser compreendidas como funcionais matemáticos que objetivam estabelecer através de processos adaptativos de correção de erros, relações que vão desde de aproximações funcionais até o reconhecimento de padrões passando pela predição de séries temporais e identificação de sistemas dinâmicos. Dessa maneira, nesta pesquisa restringe-se o uso das RNAs limitadas ao escopo de aproximadores de relações variacionais multidimensionais [18].

Assim, uma rede neural nos moldes de Mac Culloch e Pitts [37] atua como um modelo de caixapreta, recebendo as entradas do meio externo, processando-as e, por fim, gerando uma saída. Os elementos básicos constituidores de uma rede neural são os neurônios artificiais. Estes matematicamente atuam como operadores lineares, recebendo as entradas e majorando-as através de pesos sinápticos. Por sua vez, os pesos sinápticos são atualizados iterativamente através do Algoritmo da Retropropagação de erros, respeitando o modelo da Regra Delta de aprendizagem ou Widrow-Hoff Learning Rule [38].

Na Figura 1 é mostrado um modelo esquemático de uma RNA, na arquitetura Perceptron Multicamadas, cuja sua aprendizagem é realizada pela correção dos pesos sinápticos baseados na direção gradiente de uma superfície de erro, caracterizando-se assim uma aprendizagem supervisionada [18]. Esta foi a arquitetura aplicada nesta pesquisa, doravante serão apresentadas algumas topologias selecionadas para serem treinadas com intuito de realizar um mapeamento multidimensional.

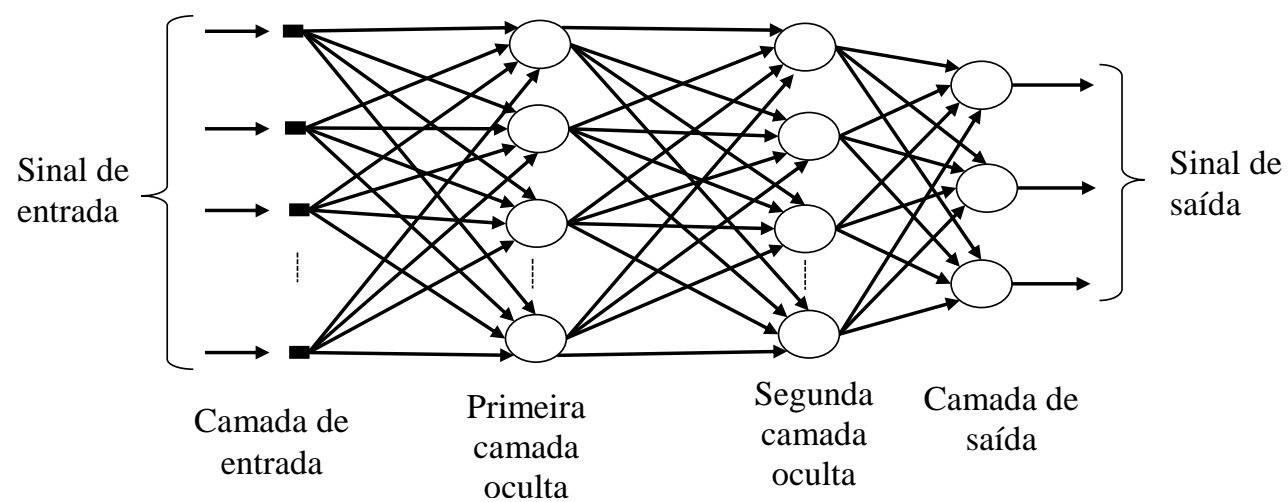

Figura 1: Modelo esquemático da Arquitetura Perceptron Multicamadas [18].

Para conceitos anteriores e para mais detalhes sugere-se consultar a seguinte lista referencial [18, 39, 40, 41]. Aplicou-se as RNA, como um elemento de aproximação, dessa forma, usou-se da discrição topológica mostrada na Tabela 7. A camada de entrada ou a camada dos neurônios sensoriais, foi definida, somente como unitária, que contém todas as cinco variáveis de entrada, conforme definidas na seção 2.4. A otimização do treinamento foi executada por intermédio do Algoritmo de Treinamento Levenberg-Marquardt [42, 43, 44].

Nota-se que o dimensionamento da quantidade de camadas ocultas e os neurônios em cada uma destas, foi definido de forma empírica. Aplicou-se na camada de saída um neurônio, cuja função de ativação foi a função linear, isto a fim de não limitar os valores da amplitude da saída. Como critério de parada, avaliou-se os seguintes caminhos: i) o primeiro definiu a função do Erro Quadrático Médio (EQM) como o indicador da performance dos treinos, ii) adotou-se como parada o limite EQM de 1E-9, iii) limitou-se a quantidade de iterações baseadas no treinamento por época num limite máximo de 300 épocas, iv) de formar similar, se a evolução incremental do gradiente for nula acorre o indicativo da parada do treinamento. 
Tabela 7: Discrição das Topologias das Rede Neurais.

\begin{tabular}{cc}
\hline Arquitetura & Perpectron Multicamadas \\
Tipo do treinamento & Supervisionado \\
Número máximo de camadas & 4 \\
Topologia 1 & $1-5-1$ \\
Topologia 2 & $1-10-1$ \\
Topologia 3 & $1-20-1$ \\
Topologia 4 & $1-5-5-1$ \\
Topologia 5 & $1-10-10-1$ \\
Topologia 6 & $1-20-20-1$ \\
Algoritmo de treinamento & Error back-propagation e Levenberg-Marquardt \\
Função de ativação nas camadas ocultas & Tangente Hiperbólica \\
Função de ativação na camada de saída & Função linear \\
\hline
\end{tabular}

Visando verificar questões relacionadas ao overfitting e underfitting [18], realizou-se a subdivisão do conjunto amostral nos grupos de treinamento, validação e testes e optou-se pelo seguinte percentual de amostras a cada um destes grupos como $70 \%, 15 \%$ e $15 \%$ respectivamente. A implementação computacional foi realizada no software ®Matlab, por meio do toolbox de Redes Neurais Artificiais [45], na versão R2014. Consequentemente, aplicou-se a função de random block para subdividir de forma randômica as variáveis dos conjuntos do grupo de entrada, respeitando a prévia alocação percentual.

A fim de avaliar a seguridade estatística dos resultados dos treinamentos, foram efetivados 50 treinamentos independentes objetivando gerar gráficos da distribuição de probabilidade cumulativa sob o parâmetro do EQM para cada treinamento da rede, ressaltando-se que não foi utilizada a reinicialização da matriz dos pesos para cada re-treino.

\subsection{Modelos funcionais de aproximação e sensibilidade numérica}

De posse do dimensionamento topológico, visto na seção 2.4 , esta proveu a generalização e a aproximação não-linear dimensionada para a Rede Neural. Implementou-se a aplicação do Método Profile (MP) [19] para aferir a sensibilidade da rede quanto a sua variável de saída, neste caso a quantidade de óbitos advindos da dengue observados na Tabela 1.

$\mathrm{Na}$ aplicação do MP, a rede neural tem suas variáveis de entrada particionadas em determinada escala, ou seja, discretiza-se uma variável de entrada, em uma quantidade desejável de pontos, e mantém-se as outras variáveis fixas. Por exemplo, na Figura 2, mostra-se uma escala de 12, enquanto as outras variáveis de entrada são mantidas inalteradas e constantes, executando-se a RNA já treinada. Assim é obtido o resultado com as variáveis de entrada tomadas em cinco pontos específicos, que são o valor mínimo, $2^{\circ}$ quartil, mediana, $3^{\circ}$ quartil e valor máximo em função do número da escala da variável particionada. Para cada um destes cinco pontos é calculada a média aritmética simples da resposta obtida pela execução da RNA.

Por fim, plota-se um gráfico da curva da resposta da rede neural nesta configuração em função da escala, resultando num 'profile' de cada variável de entrada da rede neural em relação a variável de saída. A significância é então aferida pelo valor máximo de cada curva de profile, correspondente a cada entrada individual.

\subsection{Modificação do Método Profile}

Foram realizados 200 treinamentos com a topologia da Tabela 7. Assim, subdividiu-se duas classes de treinos, aquela em que a matriz de pesos sinápticos será reinicializada em zero e aquela que não. A modificação do MP consistiu em calcular a significância das variáveis de entrada pelo valor eficaz ou do inglês Root Mean Square (RMS), da curva de profile de cada um dos 100 treinamentos em que houve a reinicialização da matriz de pesos, esta representou a primeira classe. A segunda classe avaliou a resposta da curva de profile de cada um dos outros 100 treinamentos restantes em que não há a reinicialização, avaliando a significância pelo valor máximo de cada curva de profile. Por fim, criou-se um ranque gráfico da variável de saída que dispõe da 
significância de cada variável de entrada em função das duas classes de treinamentos e consequentemente, calculou-se a média de cada curva final do ranque profile individual na situação das duas classes de treinamentos.

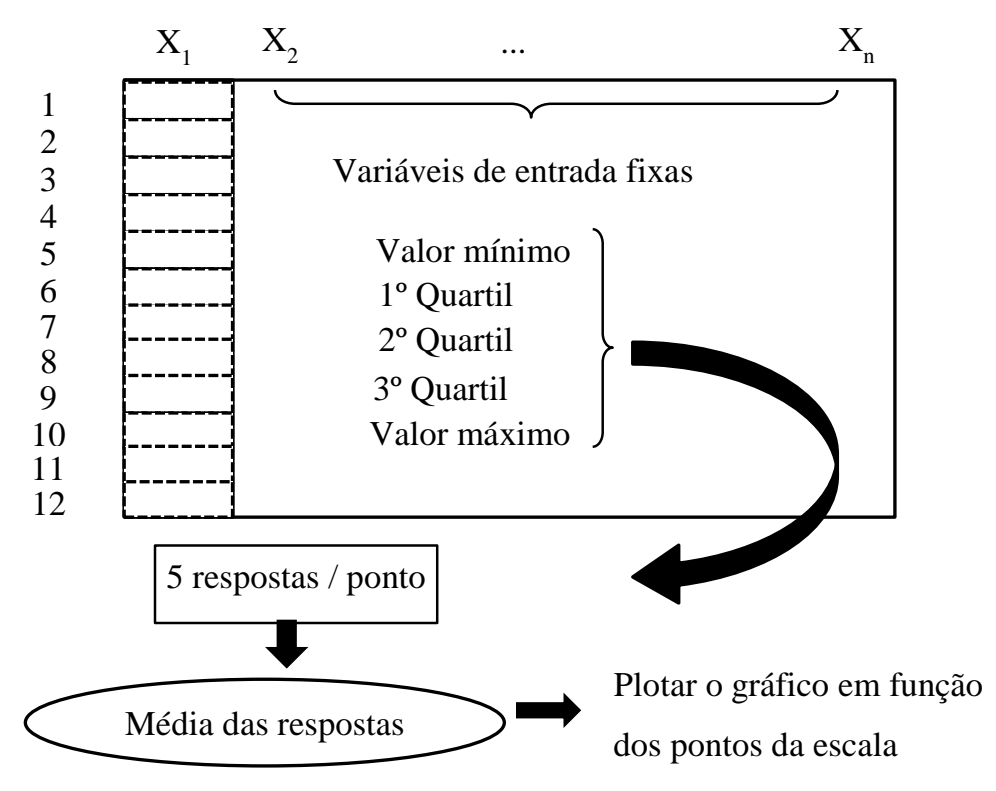

Figura 2: Modelo da implementação do Método Profile [16].

Esta modificação foi realizada com intuito de evitar e trabalhar com algumas críticas ao MP que norteiam da inabilidade e da direta dependência de randomização de matriz de pesos sinápticos, que não pode atribuir de forma analítica as devidas ponderações aos efeitos variacionais que impactam nas variáveis de saída da RNA. Muito destes pontos são observados nas pesquisas [46, $47,48]$.

\section{RESULTADOS E DISCUSSÃO}

Como evidenciado, para a devida aplicação das Redes Neurais houve a necessidade de um précondicionamento dos dados amostrais das variáveis de entrada, conforme apresentado na seção 2.4. Portanto, inicia-se por apresentar os dados refinados para a variável de entrada, IAM, que correlaciona os $65 \%$ da população da cidade de Goiânia que pratica automedicação (Figura 3a), que por sua vez é adicionado da variabilidade estatística deste percentual ao longo de 2005 à 2015 (Figura $3 b$ ).

a)

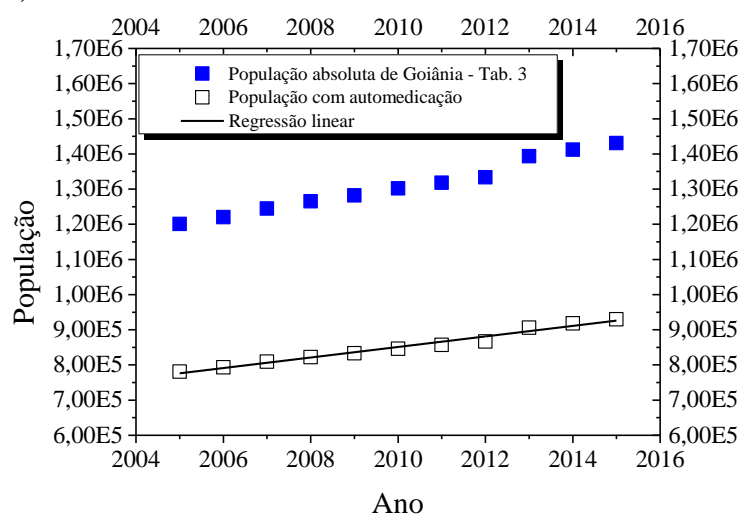

b)

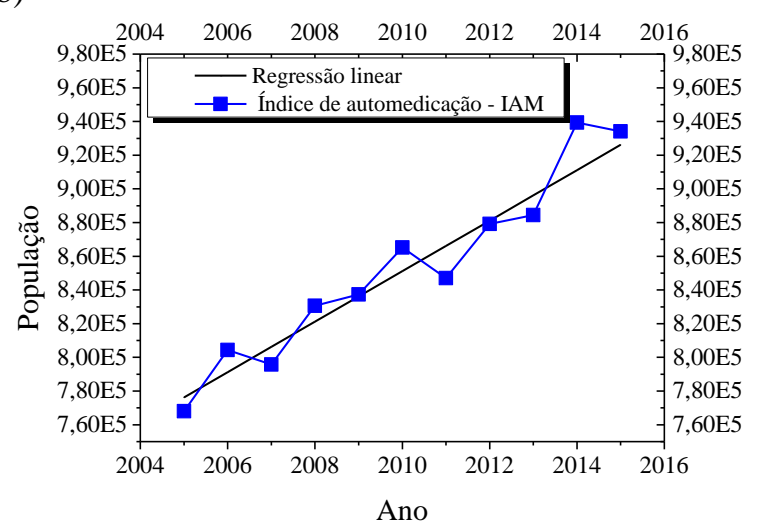

Figura 3: População de Goiânia versus ano. Caracterização da variável, IMA, constituinte da entrada da RNA. a) Obtenção da estimativa que $65 \%$ da população goianiense que comete automedicação. $b$ ) Estimativa da variabilidade estatísticas ao longo dos anos. 
Ainda na Figura 3a, o maior resíduo em módulo foi de 21795 no ano de 2012 para a curva de regressão linear, a inclinação da reta de regressão foi de 23054,04 com o intercepto em -4,50E7. De posse deste resíduo, gerou-se a estimativa estatística da variabilidade do IAM para a população de Goiânia mostrada na Figura 3b.

a)

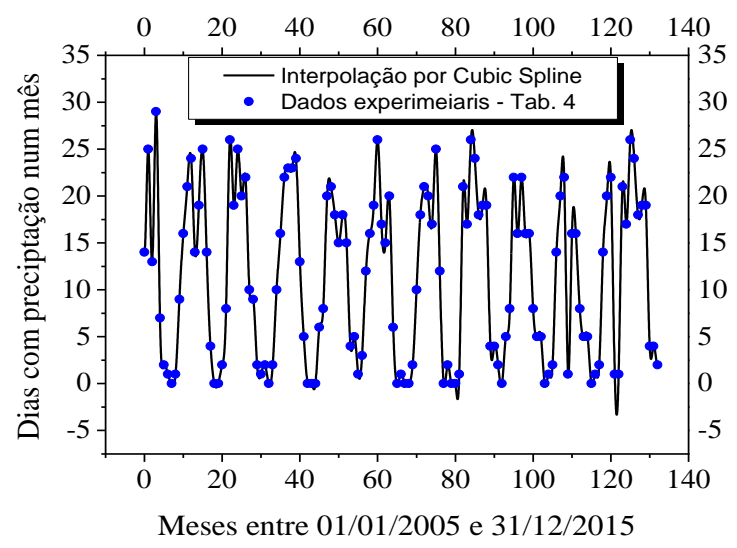

c)

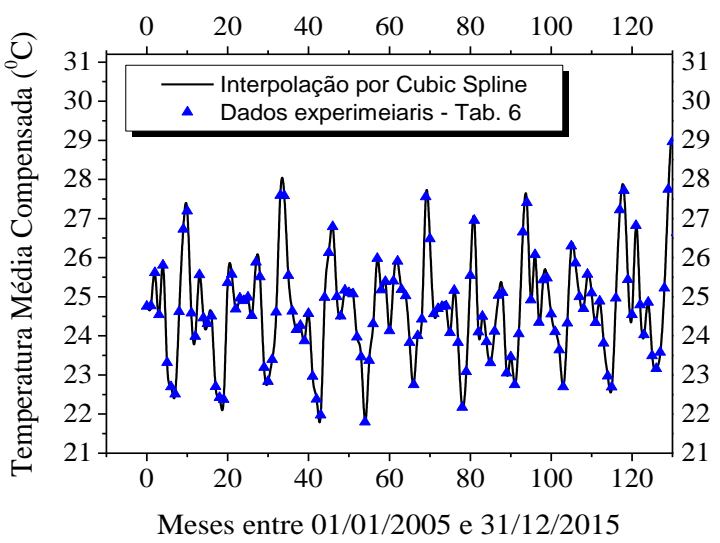

e)

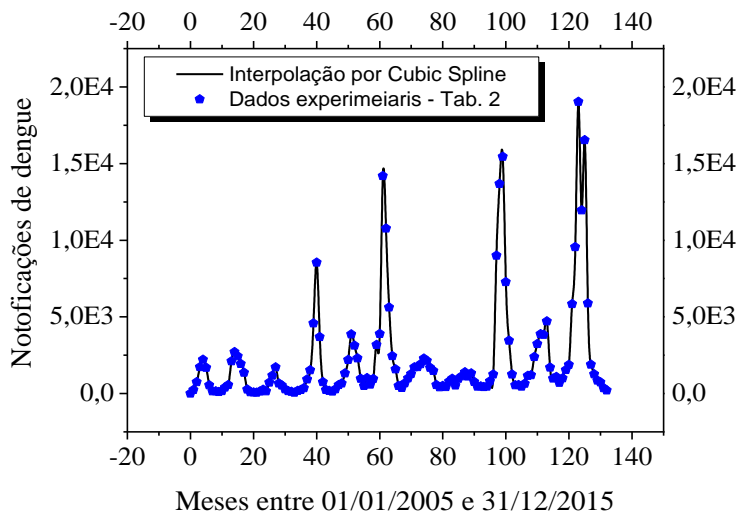

b)

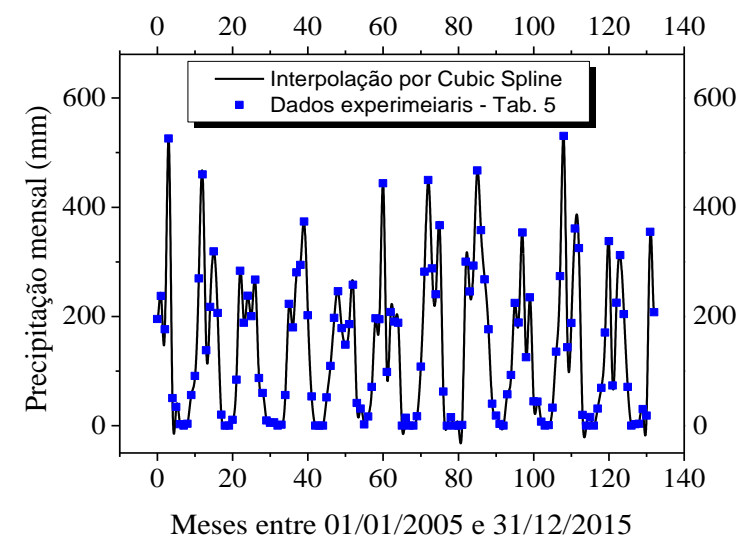

d)

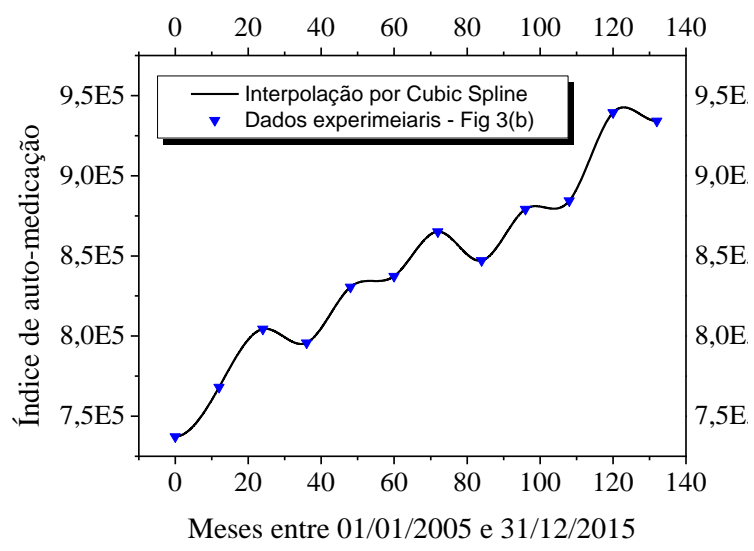

f)

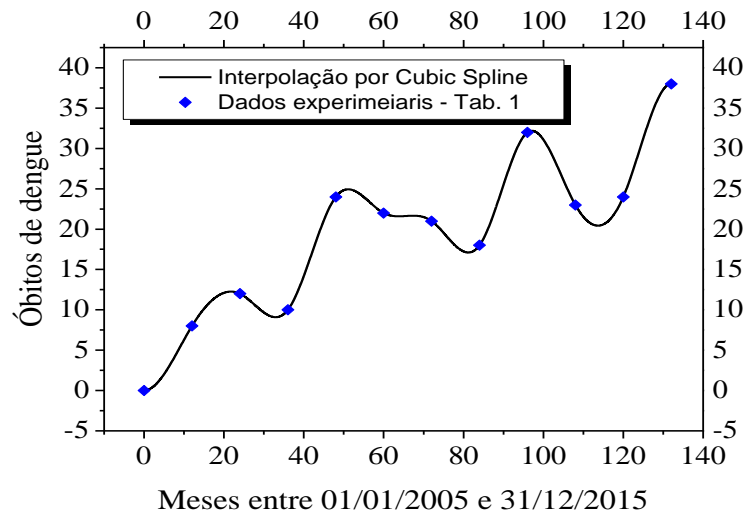

Figura 4: Plotagem das variáveis de entrada e saída da RNA versus período de tempo. a) Mostra quantos dias houve precipitação num mês - DCPM, b) Mostra a precipitação mensal, correspondente a variável $P$,

c) Mostra a evolução da temperatura, sendo caracterizada como a variável TMC, d) Estimativa da população Goianiense que faz automedicação - IAM, e) Mostra o número de notificações de dengue - ND. f) Mostra a variável de saída da RNA, nela é contida os óbitos de dengue. 
De forma similar, mostra-se na Figura 4 o quantitativo das $N D$ e as demais variáveis abióticas que constituíram-se das entradas numéricas das RNA como a $P, T M C, I A M$ e $D C P M$. Nota-se que a sensibilidade desses gráficos trata-se de dados estimados em parâmetros discretizados em dias. Conforme a seção 2.4, aplicou-se a interpolação através do Método da Cubic Spline.

A partir dos dados da Figura 4, pode-se mostrar que a correlação $R$ entre as variáveis de entrada da rede neural em relação a quantidade de óbitos são: 0,$01 ; 0,05 ; 0,14 ; 0,86$ e 0,33 em relação as variáveis $D C P M, P, T M C, I A M$ e $N D$ respectivamente. Estes dados já proveem uma indicativa de uma própria dinâmica interna que relaciona-se somente com os dados de entradas.

Por continuidade, após o tratamento inicial dos dados mostrado na Figura 4, a próxima etapa centrou-se na realização dos treinamentos das topologias definidas para as RNA, na seção 2.5, Tabela 7 e na verificação dos resultados de cada topologia para a posterior aplicação do MP.

Dessa forma, elencou-se a topologia 1-20-20-1 como a adotada para a aplicação do MP. Justificase a adoção dessa topologia pelo comparativo em relação a topologia 1-5-1, mostrada na Figura 5, que apresenta a performance em termos do erro percentual de aproximação dos óbitos de dengue em função das variáveis DCPM, P, TMC, IAM e ND entre 2005 e 2015. Logo na Figura 5b verificou-se underffiting, exemplificado pelos erros de estimativa em torno de $53 \%$, que foram os maiores dentre o range topológico, enquanto o maior erro na topologia 1-20-20-1 foi $2 \%$.

a)

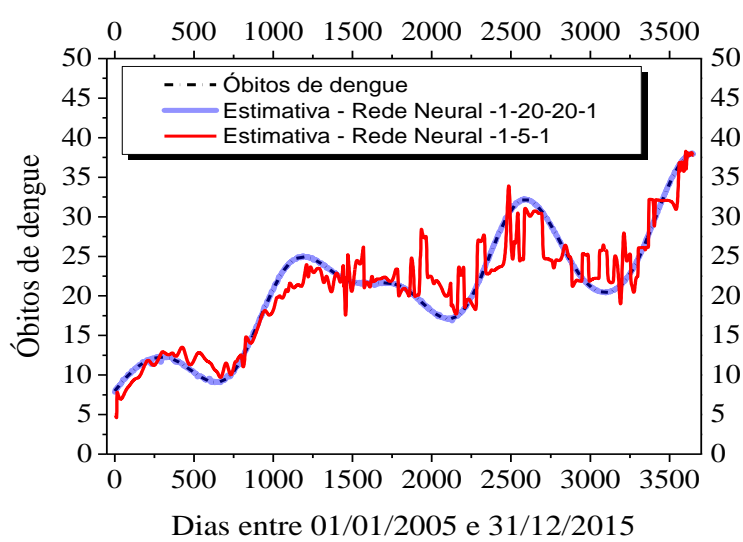

b)

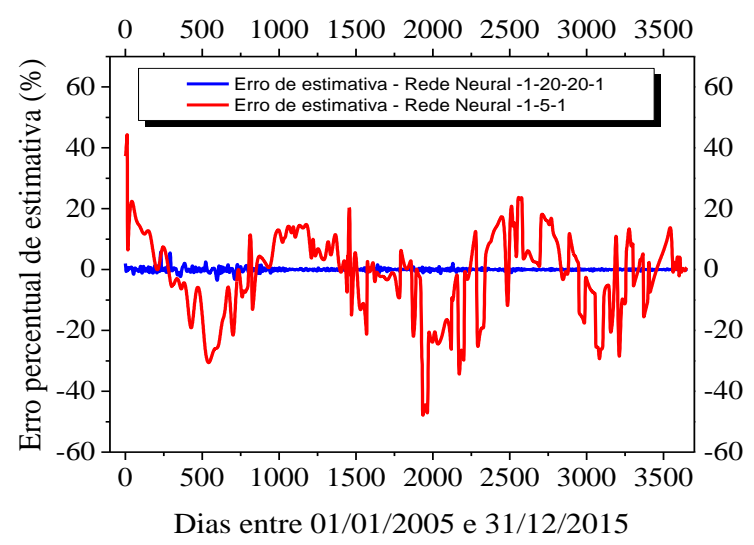

Figura 5: a) Óbitos de dengue versus tempo, comparativo da estimativa dos óbitos de dengue usando as topologias 1-5-1 e 1-20-20-, b) Erro percentual versus tempo, evidencia o underffiting para a topologia 15-1, validado por seus altos erros de estimativa, em relação aos óbitos de dengue.

Salienta-se que os resultados mostrados na Figura 5 referem-se somente a condicional de um único treinamento e fornecem o indicativo de qual topologia apresentou o melhor desempenho, em termos de aproximação do tipo de fitting não linear. Todavia, como proposto nesta pesquisa, para aferir o efeito de parâmetros exógenos, efetuaram-se 50 múltiplos treinamentos independentes.

Nesta premissa a Figura 6 corresponde ao gráfico da probabilidade cumulativa das topologias da Tabela 7 em relação a função de desempenho, EQM. Nota-se que a distribuição de probabilidade dos treinamentos não configurou-se como uma distribuição normal, cuja a distribuição probabilística deveria estar contida numa reta; fato este, corroborativo para uma distribuição não simétrica e não linear de probabilidade.

De acordo com a Figura 6, a topologia 1-20-20-1 mostrou-se a mais adequada por apresentar uma boa generalização para a variável de saída, óbitos de dengue e não apresentar underfitting ou overfitting. Consequentemente, esta topologia foi a escolhida para a posterior aplicação do MP. Sendo assim, plotou-se, conforme mostra a Figura 7, as curvas de profile das variáveis de entrada da Rede Neural. Nota-se que o profile de cada variável, foi discretizado nas escalas de 12 e 50. 
a)

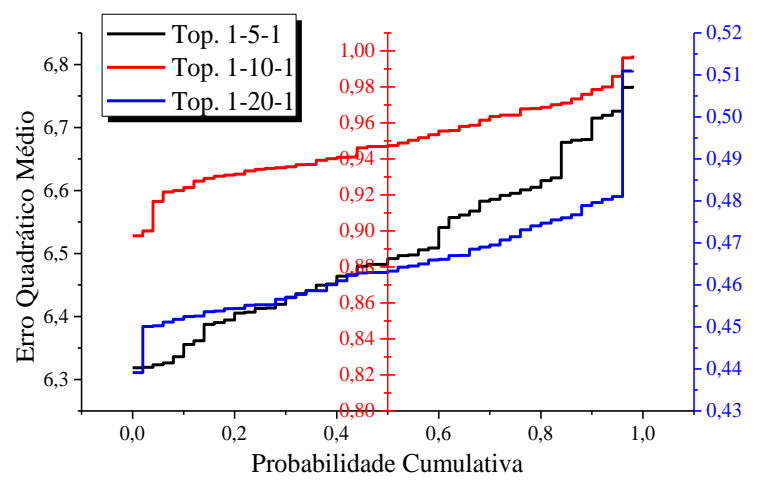

b)

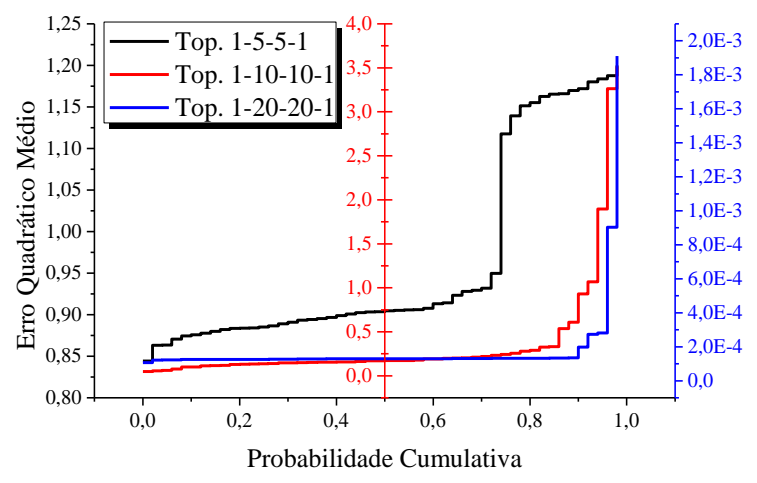

Figura 6: Erro Quadrático Médio versus Probabilidade cumulativa, a) Mostra-se os dados para as topologias com duas camadas, b) Mostra-se os dados para as topologias com três camadas.

Verifica-se por meio da Figura 7 que o aumento da escala de 12 para 50 não afetou significativamente os valores da curva de cada profile, ficando restrito ao erro máximo de $3,21 \%$, presente na Figura 6e. Portanto, os próximos resultados foram calculados com escala 50.

Como o resultado da consistência verificada na topologia 1-20-20-1, prossegue-se ao introduzir a modificação do MP nesta pesquisa, vista na seção 2.7. Ressalta-se que foram planejados dois tipos de treinamentos para essa topologia, a primeira efetuou cada novo treinamento, zerando-se as matrizes de pesos sinápticos e bias, a segunda usou como kickoff (estimativa inicial) das matrizes de pesos e bias os dados da rede neural previamente treinada. Por consequência, a Figura 8 mostra a dinâmica evolucional do EQM para essas duas situações.

Nota-se que na curva da Figura 8a obteve-se um valor médio do EQM de 0,22, com desvio padrão de 1,47, em contrapartida, a média para a curva sem a inicialização em zero foi de 4,52E-5, com o desvio padrão de 3,21E-5. Por consequência, com o valor de $\mathrm{R}=0,03$, logo comprova-se que estas curvas não apresentaram nenhuma correlação, inferindo que as matrizes de pesos sinápticos são díspares em ambos os casos. Dessa forma, assegura-se a introdução de certa aleatoriedade, cobrindo casos desfavoráveis de classificação com significâncias duvidosas para altos EQM, que geram underfitting.

Após a confecção dos 100 treinamentos múltiplos e independentes, conforme mostrados na Figura 8, foi possível construir as curvas de classificação de significância das variáveis de entrada da rede neural (Figura 9) em função das duas situações relacionadas as matrizes de pesos sinápticos, com e sem reinicialização. Ressalva-se a introdução da modificação do MP, descrita na seção 2.6.

Portanto, tem-se na Figura 9a a classificação de significância ao ponderar o efeito global da contribuição de cada RNA na alocação da significância para as 5 variáveis de entrada, sendo calculada pelo valor máximo respectivo da curva de profile dessa rede. Um ilustrativo seria o valor máximo para a curva da Figura 7a, correspondente a variável de entrada, $N D$, para um dos 100 treinamentos qualquer, sem a inicialização. Deste modo, com 100 treinamentos houve 100 classificações de significância. De forma análoga, tem-se na Figura $9 b$ a classificação de significância com a inicialização em zero, o valor de referência nesta situação foi o valor eficaz, RMS da curva de profile.

Assim sendo, tem-se mostrado na Tabela 7 a classificação em termos de significância das variáveis que mais impactam nos óbitos de dengue durante o período de 2005 a 2015 , na cidade de Goiânia. 
a)

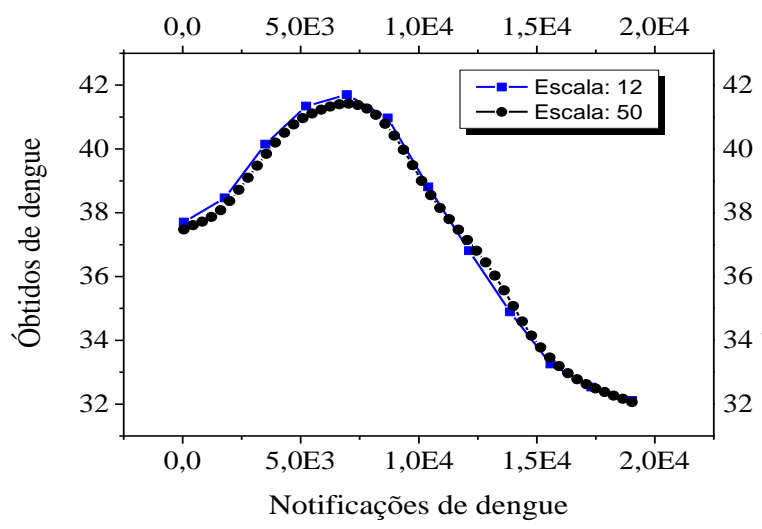

c)

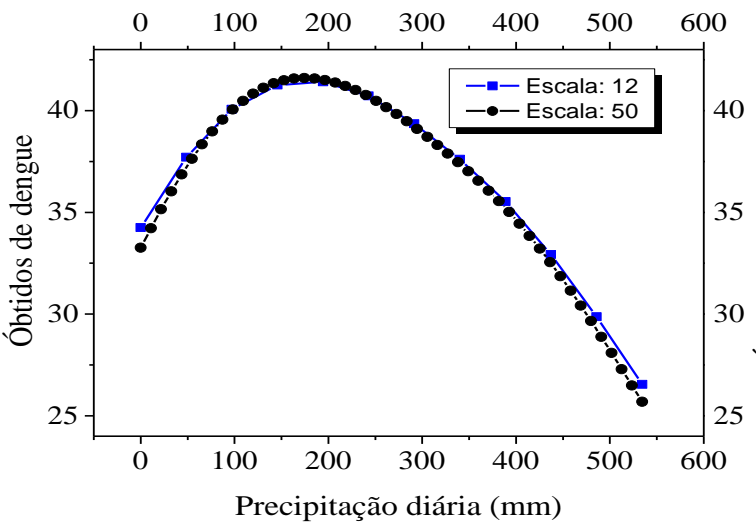

b)

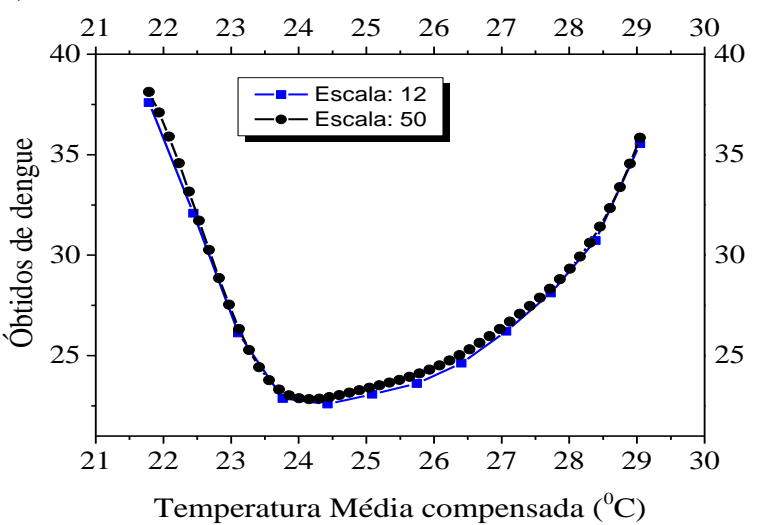

d)

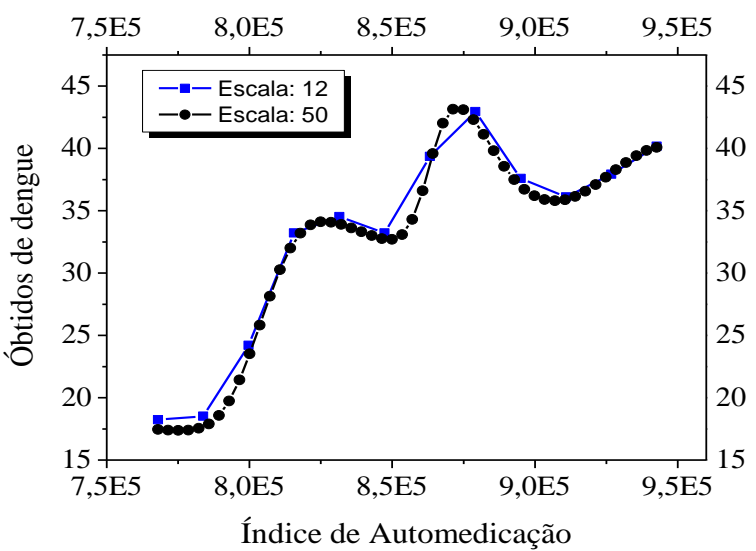

e)

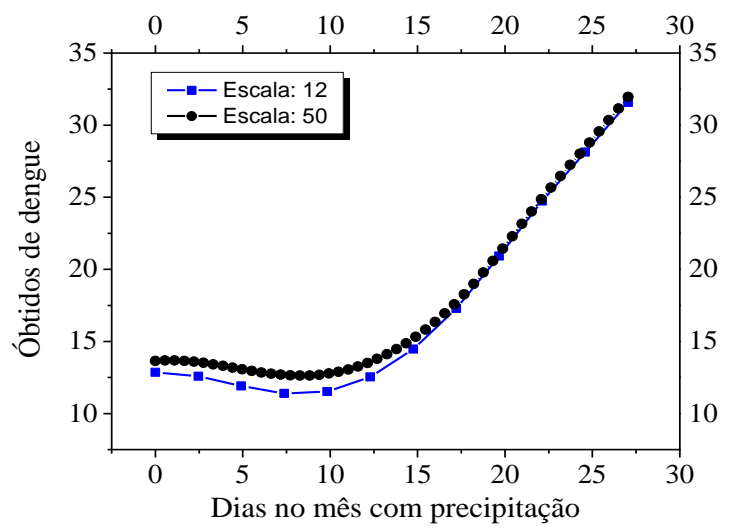

Figura 7: Curvas do profile variacional de cada entrada da Rede Neural, mostrando seu impacto na variável de saída. a) Óbitos de dengue versus Notificações - (ND), b) Óbitos de dengue versus Temperatura Média Compensada - (TMC), c) Óbitos de dengue versus Precipitação diária - (P), d) Óbitos de dengue versus Índice de Automedicação - (IMA), e) Óbitos de dengue versus Dias no mês com precipitação-(DCM). 
a)

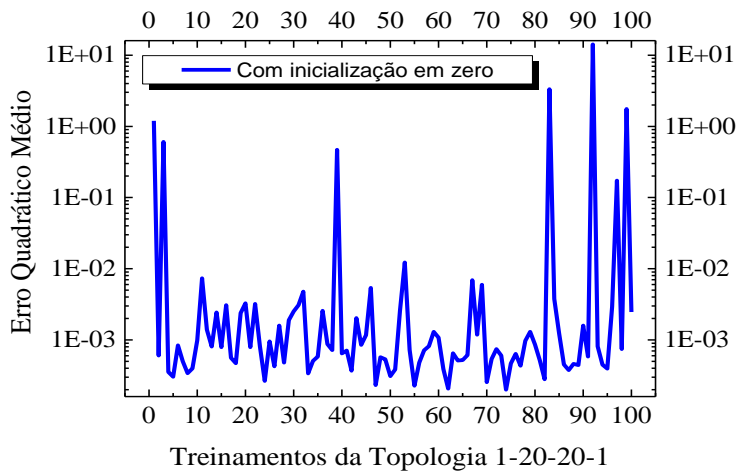

b)

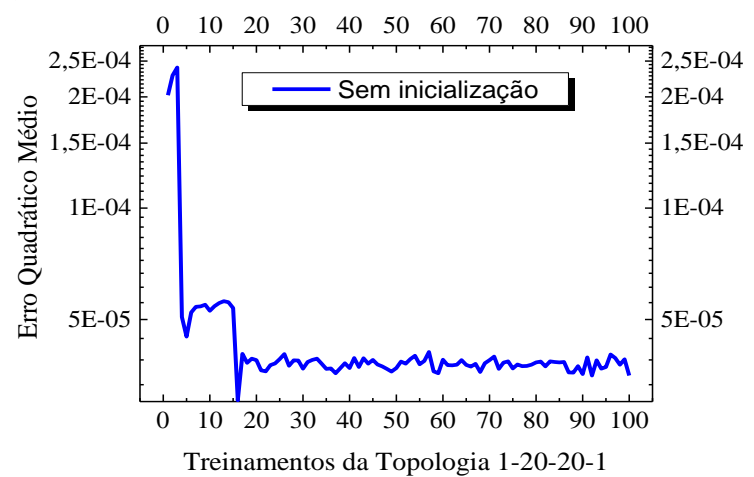

Figura 8: Erro Quadrático Médio versus Treinamento. a) Evidencia a evolução semicaótica da variabilidade das magnitudes do EQM, pois em cada treino há uma nova matriz de pesos sinápticos, $b$ ) Evidencia certo padrão de regularidade acerca da magnitude do EQM, em cada novo treino, a matriz de pesos sinápticos pouco se altera.

a)

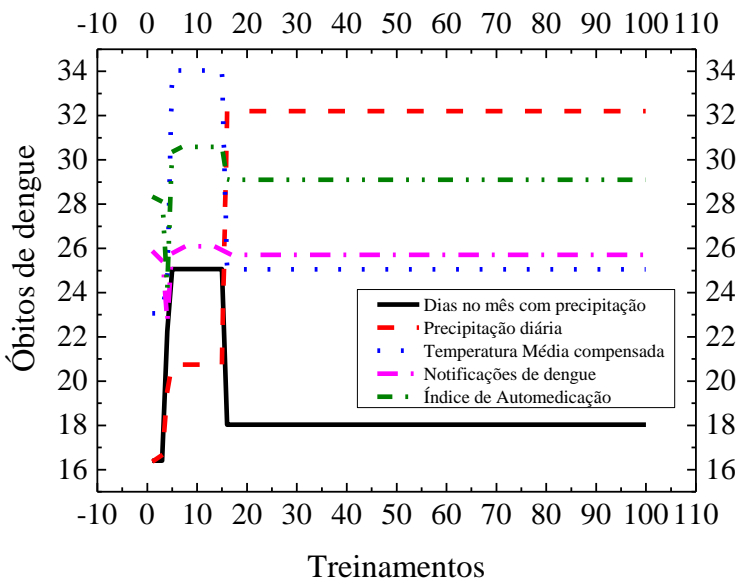

b)

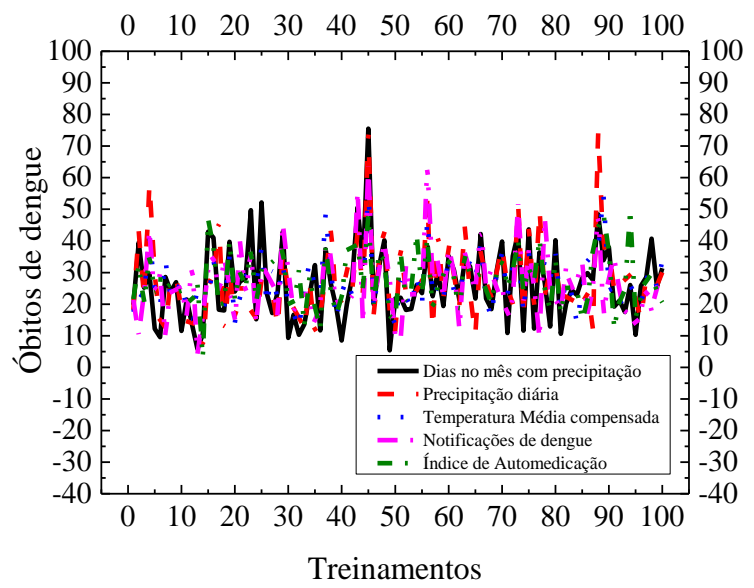

Figura 9: Óbitos de dengue versus treinamentos. Estes gráficos, mostram a relação da contribuição individual de cada entrada da RNA, no valor da saída, óbitos de dengue, logo realizando a classificação das entradas por magnitude de impacto. a) Classificação de significância sem a inicialização, b) Classificação de significância com a inicialização.

Tabela 7: Classificação de Significância dos fatores abióticos associados aos óbitos de dengue

\begin{tabular}{ccccccc}
\hline & \multicolumn{5}{c}{ Tipo do classificador de Significância } \\
\cline { 2 - 7 } $\begin{array}{c}\text { Variável de } \\
\text { entrada }\end{array}$ & \multicolumn{2}{c}{ Sem inicialização - Profile. Max. } & \multicolumn{2}{c}{ Com inicialização - RMS Profile. } \\
\cline { 2 - 6 } & Significância & $\begin{array}{c}\text { Desvio } \\
\text { padrão }\end{array}$ & Ranque & Significância & $\begin{array}{c}\text { Desvio } \\
\text { padrão }\end{array}$ & Ranque \\
\hline $\boldsymbol{D C P M}$ & 18,80 & 2,27 & 5 & 26,24 & 12,00 & 5 \\
$\boldsymbol{P}$ & 30,34 & 4,50 & 1 & 26,83 & 12,87 & 2 \\
$\boldsymbol{T} \boldsymbol{M C}$ & 25,98 & 2,87 & 3 & 26,76 & 8,89 & 3 \\
$\boldsymbol{N D}$ & 25,73 & 0,33 & 4 & 26,46 & 11,42 & 4 \\
$\boldsymbol{I A M}$ & 29,19 & 0,71 & 2 & 27,71 & 9,03 & 1 \\
\hline
\end{tabular}

Uma análise centrada na literatura sugere alta concordância dos resultados obtidos pela Tabela 7 com os fatores bióticos associados ao desenvolvimento larval, que dependem intrinsecamente da pluviosidade e da temperatura, pois estes são os responsáveis pela inicial proliferação do vetor. Dessa forma, a precipitação configurou-se como o principal fator de incidência de dengue, fato este 
mostrado em outras pesquisas [20,21, 22], o que certifica e valida a precipitação como o parâmetro principal de significância nos óbitos de dengue, conforme a Tabela 7, que usou as RNA sem inicialização como classificador.

Em outro sentido, verificou-se que os fatores $T M C, N D$ e $D P C M$ ocuparam respectivamente a $3^{\mathrm{a}}, 4^{\mathrm{a}}$ e $5^{\mathrm{a}}$ posição, sendo de tal modo considerados fatores de moderada e baixa significância na influência aos óbitos. O resultado da moderada significância da temperatura mostra-se alinhado as pesquisas que postulam a não mais direta dependência de temperatura no desenvolvimento larval ou na densidade dos vetores para a efetiva contaminação de DENV, sugerindo uma adaptação do vetor as mais díspares condições de temperatura do Globo [49, 50]. Também fica evidente que o $N D$ e a quantidade dos vetores não estão diretamente associados ao desenvolvimento de complicações da dengue, dado ao coeficiente de correlação de 0,33 (Tabela 1), e que foi validado pela alocação na Tabela 7.

Não há muitas pesquisas relacionando de forma direta os óbitos por dengue com o uso irracional de medicamentos, nota-se que segundo a Tabela 7 o IAM foi alocado para a RNA com inicialização como o principal fator de significância nos óbitos, enquanto a RNA sem inicialização classificou esta na segunda posição. É lícito supor que o IAM está diretamente arrolado a população de Goiânia, e também foi possível mostrar que os AINES formam os principais medicamentos na automedicação [11], fato este pode tornar-se um fator agravante na dengue levando a quadros hemorrágicos [15]. Uma recomendação da Organização Mundial da Saúde, quanto o manejo de pacientes, em afirmar de maneira categórica a contraindicação de AINES, como o ácido acetilsalicílico e a dipirona [51,52,53], acaba por reconhecer os potenciais risco da automedicação.

\section{CONCLUSÕES}

Centrado no caráter explanatório desta pesquisa, foi possível mostrar que as Redes Neurais Artificiais atuaram de forma eficaz e proveram resultados em plena concordância com a literatura especializada, que tange no desenvolvimento e na proliferação do vetor da dengue; classificando a precipitação e a automedicação como fatores de alto risco correlatos aos óbitos de dengue. Portanto, conclui-se que as RNAs classificaram de forma inédita estes dados e suas correlações populacionais, indicando que a automedicação e precipitação pluviométrica são os principais fatores correlatos aos óbitos de dengue, seguidos das correlações intermediárias da temperatura e do número de notificações e com mínima correlação o número de dias com precipitação pluviométrica durante o mês.

\section{AGRADECIMENTOS}

Os autores são gratos à Comissão de Aperfeiçoamento de Pessoal do Nível Superior (CAPES) fomentado pela Fundação de Amparo à Pesquisa do Estado de Goiás (FAPEG), conforme os editais CAPES/FAPEG 05-2014 sob o fomento $\mathrm{n}^{\circ} 201410267001375$ e CAPES/FAPEG 10-2014 $\mathrm{n}^{\circ}$ 201510267000418.

\section{REFERÊNCIAS BIBLIOGRÁFICAS}

1. Maciel IJ, Siqueira Jr JB, Martelli, CM. Epidemiologia e desafios no controle do dengue. Rev Patol Trop. 2008 Mai; 37(2):111-130.

2. Teixeira MG, Barreto ML, Guerra Z. Epidemiologia e medidas de prevenção do dengue. Informe Epidemiológico do SUS. 1990 Dez; 8(4):5-33.

3. Zara AL et al. Estratégias de controle do Aedes aegypti: uma revisão. Epidemiol Serviços Saúde. 2016 Abr. 25(2):391-404. doi:10.5123/S1679-49742016000200017

4. Condino ML et al. Associação entre incidência de dengue e variáveis climáticas. Rev Saúde Pública. 2006 Mar.40(4):671-6.

5. Musial DC, Josiene SD, Tânia CA. A automedicação entre os brasileiros. SaBios-Rev Saúde e Biologia. 2007 Jan; 2(2):5-8.

6. Dos Santos F, Luciano A, Arthur AB, Carllini BV. Avaliação necroscópica de choque circulatório por complicações hemorrágicas: Dengue. Rev Patol Tocantins. 2015 Jan;2(3):29-37. 
7. Gorzoni ML, Irineu FD, Sueli LP. Dengue in an elderly patient. Rev Inst Med Trop São Paulo. 2010 Maio; 52(3):163-167.

8. Regina MP et al. Doenças exantemáticas e primeira epidemia de dengue ocorrida em Manaus, Amazonas, no período de 1998-1999. Rev Soc Bras Med Trop. 2004 Nov; 37(6):476-479.

9. Mourão MP. Abordagem Sindrômica de Doenças Febris Agudas [Tese]. Brasília (DF): Universidade de Brasília; 2007. $356 \mathrm{p}$.

10. Vitor RS et al. Padrão de consumo de medicamentos sem prescrição médica na cidade de Porto Alegre, RS. Ciência \& Saúde Coletiva. 2008 Mar; 13:737-743. doi:10.1590/S1413-81232008000700024.

11. Arrais PS et al. Perfil da automedicação no Brasil. Rev Saúde Pública. 1997; 31(1):71-7.

12. Bortolon PC et al. Análise do perfil de automedicação em mulheres idosas brasileiras. Ciência \& Saúde Coletiva. 2008 Jan;13(4):1219-1226

13. Mastroianni PC et al. Estoque doméstico e uso de medicamentos em uma população cadastrada na estratégia saúde da família no Brasil. Rev Panam Salud Publica. 2011 Out; 29(5):358-64.

14. Lenzi MF, Coura LC.Prevenção da dengue: a informação em foco. Rev Soc Bras Med Trop. 2004 Jul; 37(4): 343-350.

15. Díaz-Quijano FA, Luis VC, Ruth AM. Efecto de la administración temprana de dipirona sobre la gravedad del dengue en una cohorte prospectiva. Enferm Infecc Microbiol Clínica. 2005 Out;23(10):593-597. doi: $10.1157 / 13081567$.

16. Ministério da Saúde (BR). Secretaria de Vigilância em Saúde. Departamento de Vigilância Epidemiológica. Diretrizes Nacionais para Prevenção e controle de Epidemias de Dengue - Série A. Normas e Manuais Técnicos. Brasília (DF), Brasil. 2009.

17. Sandra MS et al. Estimativa de custos diretos do Programa Municipal de Controle da Dengue de GoiâniaGO. Epidemiol Serv Saúde. 2015 Dez; 24(4):661-670.

18. Haykin S. Redes Neurais - Princípios e Práticas. Porto Alegre: Bookman; 2 ed. 2001. 900 p.

19. Lek S, et al. Role of some environmental variables in trout abundance models using neural networks. Aquat Living Resour. 1996 Jan; 9:23-29. http://dx.doi.org/10.1051/alr:1996004

20. Kuno G. Review of the factors modulating dengue transmission. Epidemiol Rev. 1995; 17(2):321-335.

21. Souza SS, Ionizete GS, Heloísa HG. Associação entre incidência de dengue, pluviosidade e densidade larvária de Aedes aegypti, no Estado de Goiás. Rev Soc Bras Med Trop. 2010 Jan, 43(2):152-155.

22. Viana DV, Eliane I. A ocorrência da dengue e variacões meteorológicas no Brasil: revisão sistemática. Rev Bras Epidemiol. 2013;16(2):240-256. doi:10.1590/S1415-790X2013000200002.

23. Goiânia. Secretaria Municipal de Saúde de Goiânia. SMS. Informe Técnico Semanal da Dengue. Prefeitura Municipal de Goiânia, 2013. Disponível em: < http://www.saude.goiania.go.gov.br/informedengue.shtml> Acessado em: 15/09/2016.

24. Sinan. Sistema de informação de agravos de notificação. Disponível em: < http://dtr2004.saude.gov.br/ sinanweb/tabnet/dhsinannet/dengue/bases/denguebrnet.def > Acesso em: 20/10/2016.

25. Brasil - Instituto Brasileiro de Geografia e Estatística. População residente enviada ao Tribunal de Contas da União - 2001-2015. Disponível em: < http://www.ibge.gov.br/home/estatistica/populacao/estimativa 2015 /serie_2001_2015_tcu.shtm > Acesso em: 17/10/2016.

26. Cascaes EA, Falchetti ML, Galato D. Perfil da automedicação em idosos participantes de grupos da terceira idade de uma cidade do sul do Brasil. Arq Cat Med. 2008 Set; 37(1):63-39.

27. Monteiro SC, Azevedo LS, Belfort IK. Automedicação em idosos de um programa saúde da família, Brasil. Infarma-Ciências Farmacêuticas. 2014 Out; 26(2):90-95.

28. Paim RS, et al. Automedicação: uma síntese das publicações nacionais. Rev Contexto \& Saúde. 2016; $16(30): 47-54$

29. Santos TR, et al. Consumo de medicamentos por idosos, Goiânia, Brasil. Rev Saúde Públ. 2013 Jan; 47(1): 94-103.

30. Souza LA, et al. Prevalência e caracterização da prática de automedicação para alívio da dor entre estudantes universitários de enfermagem. Rev Latino-Am Enfermagem. 2011 Jan; 19(2):245-251.

31. Instituto de Pesquisa e Pós-Graduação do Mercado Farmacêutico - ICTQ. Pesquisa sobre uso racional de medicamentos no Brasil. 2014. Disponível em: < http://www.ictq.com.br/component/tags/tag/24farmacia > Acessado em: 25/09/2016.

32. Costa HC, et al. Espacialização e Sazonalidade da Precipitação Pluviométrica do Estado de Goiás e Distrito Federal. Rev Bras Geogr Fís. 2012 Fev;5(1):87-100.

33. Brasil - BDMEP. Banco de Dados Meteorológicos para Ensino e Pesquisa, Disponível em: < http://www.inmet.gov.br/projetos/rede/pesquisa/ >. Acesso 17/09/2016.

34. Nimer Edmon. Climatologia do brasil. Secretaria de Planejamento da Presidência da República, Fundação Instituto Brasileiro de Geografia e Estatística, Diretoria Técnica, Superintendência de Recursos Naturais e Meio Ambiente, vol. 4. 1979. 
35. Montgomery DC, Runger GC. Applied Statistics and Probability for Engineers. 5 ed. Wiley, New York, $2011.768 \mathrm{p}$.

36. De Boor C., et al. A practical guide to splines. vol. 27. New York: Springer-Verlag, 1978. 341 p.

37. Macculloch W, Pitts W. A Logical Calculus of Ideas Immanent in Nervous Activity. Bull Math Biophys 1943;5:115-133.

38. Widrow B, Hoff ME. Adaptive switching circuits. In: 1960 IRE WESCON convention record, New York. p. 96-104, 1960.

39. Hagan MT, Demuth HB, Beale M. Neural Network Design. 2 ed. Ebook, 2013, 1020 p.

40. Bishop CM. Neural Networks for Pattern Recognition. Oxford - UK:Clarendon Press. 1995. 482 p.

41. Russell JS, Norvig P. Artificial Intelligence - A modern approach. New Jersey - USA:Prentice Hall, 1995. 1 ed. 932 p.

42. Marquardt D. An algorithm for least-squares estimation of nonlinear parameters. SIAM J. Appl. Math. 1963 Jul;11(2):431-441. doi:10.1137/0111030.

43. Levenberg K. A method for the solution of certain problems in least squares. SIAM J. Numer Anal. 1944 Jul;2(2):164-168.

44. Hagan MT, Menhaj M. Training feedforward networks with the Marquardt algorithm. IEEE Tran Neu N. 1994 out; 5(6):989-993. doi:10.1109/72.32969.

45. Beale, Mark; Hagan, Martin T.; Demuth, Howard B., Neural network toolbox. Neural Network Toolbox - version R2014a. The Math Works. 2014. 435 p.

46. Nascimento EO, Oliveira LN. Sensitivity analysis of cutting force on milling process using factorial experimental planning and artificial neural networks. IEEE Lat Am T. 2016; Dec: 14 (12): 4811-4820.

47. Olden JD, Joy MK, Death RG. An accurate comparison of methods for quantifying variable importance in artificial neural networks using simulated data. Ecol Model. 2004 Nov;178(3):389-397. doi:10.1016/j.ecolmodel.2004.03.013.

48. Gevrey M, Dimopoulos I, Lek S. Review and comparison of methods to study the contribution of variables in artificial neural network models. Ecol Model. 2004 Feb;160(3):249-264. http://dx.doi.org/10.1016/S0304-3800(02)00257-0.

49. Morin CW, Andrew CC, Kacey E. Climate and dengue transmission: evidence and implications. Environ Health Perspect. 2013; 121(11-12):1264p. http://dx.doi.org/10.1289/ehp.1306556.

50. Kristie LE, Joshua N. Dengue in a changing climate. Environ Res. 2016 Nov;151:115-123. http://dx.doi.org/10.1016/j.envres.2016.07.026.

51. World Health Organization. Dengue: guidelines for diagnosis, treatment, prevention and control. World Health Organization, 2009. $147 \mathrm{p}$.

52. World Health Organization. Handbook for clinical management of dengue. Geneva, Switzerland: World Health Organization, 2012. $111 \mathrm{p}$.

53. Rajapakse S, Chaturaka R, Anoja R. Treatment of dengue fever. Infect Drug Resist. 2012 Jul;5(1):10312. https://dx.doi.org/10.2147/IDR.S22613. 